\title{
Building a Knowledge-Based Economy in Bangladesh
}

\section{Md. Qamruzzaman, Jannatul Ferdaous}

Lecturer, School of Business Studies, Southeast University, Bangladesh

\begin{abstract}
The concept of "knowledge economy" is based on the view knowledge and information are at the center of economic growth and development. In today's ever changing world knowledge has become a key element for sustainable economic development. This study aims to identify key challenges for developing knowledge based economy in Bangladesh. Study results revealed that key challenges faced by Bangladesh are reluctant of economic sectors to become accustomed IT based operation rather than traditional practice and lack of skilled manpower. To overcome those challenges concerted efforts are imperative by implementing a comprehensive strategy based on research and sound economic principles, help use of ICT in businesses and Government sector and Investment in human capital.
\end{abstract}

Key words: knowledge economy, productivity, ICT, development, R\&D

JEL codes: R120, D 830

\section{INTRODUCTION}

In the last couple of decades, many countries have made significant economic gains by knowledge creation and diffusion to the various sectors of the economy. The term "knowledge economy" refers either to an economy of knowledge or to a knowledge-based economy focused on the production and management of knowledge within the framework of economic constraints. In a knowledge economy, knowledge is considered as a public good because knowledge leaks and it is very difficult for a country to retain knowledge just for its own advantage for any length of time. It is often said the value of knowledge to an economy comes from sharing with others. The arrival of the knowledge-based economy is seen as an opportunity for developing countries for transforming the economy from manufacturing conventional goods to knowledge-intensified goods. With sustained use and creation of knowledge at the center of the economic development process, an economy essentially becomes a Knowledge Economy. A Knowledge Economy (KE) is one that utilizes knowledge as the key engine of economic growth, an economy where knowledge is acquired, created, disseminated and used effectively to enhance economic development. The emergence of knowledge-based economy provides the platform for rapid economic growth and also enhance competitiveness by complementing and accelerating the economic system from being input-driven to productivity driven. The emergence of a knowledge-based economy has been associated with endless productivity gains and faster noninflationary growth. It was also observed in knowledge based economy that ICT revolution allowed economy to exploit scientific and technical knowledge bases for achieving an unprecedented competitive edge through reduction of transaction and processing costs.

\section{The KnOWLedge-based Economy: What does IT MEAN?}

There are many who argue that we are moving towards a new "knowledge economy" in which the role and significance of knowledge for economic activities has fundamentally changed. This change rests on advances in information technology, which are resulting in a 'paradigm shift' in turn, involving basic changes in the economic rules of the game for both business and policymakers. Proponents of such views can be found in business, in policy-making, and in innovation analysis. But what does it mean to speak of the knowledge economy? It appears that, there is no coherent definition, let alone theoretical concept, of this term: this is a widely-used metaphor, rather than a clear concept.

The knowledge-based economy is one where the generation and utilization of knowledge contribute to a significant part in economic growth and wealth creation. It is characterized by knowledge-based activities having high-technology industries accounting for a significant share of employment, Gross Domestic Product (GDP) and exports. Besides being a factor of production, knowledge will become a commodity to be traded.

There are numerous terms that can be found in the literature which are used to describe this phenomenon.

Asia Pacific Economic Cooperation (APEC) and the Organization for Economic Cooperation and Development (OECD) define that the knowledge economy is a term that is associated with new skills, high performance and new added value as the only way for enterprises and countries to compete in the global economy. According to the OECD, the role of knowledge has gained importance (compared to natural resources, physical capital and unqualified work force). With different levels of progress all of the OECD countries are moving towards the economy based on 
knowledge. Another view on the knowledge economy defines it as the application of knowledge based industries where the knowledge becomes the key competence.

A wider view on the knowledge economy has been developing in the past few years.

Sheehan and Grewal (2000), OECD, APEC and World bank have presented a much more comprehensive definition of the term knowledge economy as an economy in which the use of knowledge is the key enabler of better productivity and growth in all industries. Economic success is based on effective use of non-material assets like knowledge, skills and potential for innovation as a key source of competitive advantage. This view of the knowledge economy opens new possibilities and gives hope to transition economies regardless of their size, availability of natural resources, level of industrialization, level of economic development. From the various definitions of knowledge economy, it is possible to formulate its general characteristic as follows: It is the economy which is directly based on the production, distribution and use of knowledge and information. Knowledge-based economy is characterized by a high and growing intensity of ICT usage by welleducated workers.

A definition of knowledge and the stylized characteristics of a knowledge based economy (World Bank, 2008):

Knowledge and Characteristics of a Knowledge-Based Economy

- Knowledge is information that is interpreted and used by decision-makers to meet their goals. It is a public good, in that, there is no additional cost when shared with other users and others cannot be excluded from using it once it is created.

- Knowledge is generally divided into two types, namely, knowledge about technology and knowledge about the attributes or tacit knowledge. The latter refers to knowledge gained from experience and which is often a source of competitive advantage.

Characteristics of a knowledge-based economy:

a) Have abundant resources. Unlike most resources that deplete when used, the knowledge input is ever expanding in tandem with technology and innovation.

b) No location barrier. Innovation in technology opens access to resources and markets all over the world, creating virtual market places and organizations. There will be increased mobility of workers and capital.

c) A highly educated labor force. The knowledge economy comprises a better-informed populace as the government invests more on human development. Workers contribute to ideas, skills and knowledge by using latest technology.

d) A high level of per capita wealth. Knowledge-based investments generate increasing returns to scale and therefore, more wealth for all.

e) Open cosmopolitan society attractive to global talent. There will be ample opportunities for locals to tap foreign knowledge and learn about best business practices as world-class infrastructure will encourage foreign investment. The population will be willing to accept and put into practice new ideas and technologies and hence, local companies will become fit and fully equipped to face global challenges.

f) Well connected to other global knowledge nodes. Connectivity to the rest of the world and technology sharing as well as technology transformation will be made easy with the free flow of information with lower cost, and reliable infrastructure encourage information and technology sharing.

g) A shift from top-down hierarchical organizational structures to flatter shared-structures such as networks of semi-autonomous teams. IT development and communications technology will lead to better interaction among workers and there will be active involvement of workers in contributing ideas and decision-making.

h) Skills and knowledge are key assets. Skills and knowledge become the main assets in the economy to gain competitiveness.

i) Information and communications technologies (ICTs) are the pillars of the knowledge-based economy. Access to networking is essential in acquiring and disseminating knowledge and the Internet is a key driver of ICT, especially in the development of E-based activities, resulting in new approaches to doing things.

\section{LITERATURE REVIEW}

The concept of the Knowledge-Based Economy (KBE) was first introduced by the OECD, which defined it as an economy which is directly based on the production, distribution and use of knowledge and information (OECD, 1996). Later, APEC (Asia-Pacific Economic Cooperation Forum) (2000\&2004) and the WBI (World Bank Institute) (1999) referred to KBE as an economy in which the production, distribution and use of knowledge are the main driver of growth, wealth creation and employment across all industries. The Economy is stronger and more directly rooted in the production, distribution and using of knowledge than even before because new ideas and innovation produce comparative advantage of KBEs(Lundwall, 1996).

In 1999 the World Bank Institute launched a project entitled "Knowledge for Development" (K4D). Its aims were to raise awareness among national policymakers about the powerful growth effects of knowledge and to encourage economists to combine global and local knowledge in order to accentuate comparative advantages (World Bank, 2008).

Jones(1999) Suggested that knowledge based economy represented "the fundamental changing of the economy based primordially on the physical resources to the economy based primordially on knowledge,It has been determined that successful transition to the knowledge economy often includes four elements: long-term investments in education, 
the development of innovation capability, the modernization of the information infrastructure and the creation of a conducive economic environment.

A Knowledge-Based Economy (KBE) is shaped not only by the development and diffusion of computer hardware and software, but also buy cheaper and rapidly increasing electronic connectivity (M.Daley, 2000). In economic terms, the main feature of the IT revolution is the ability to manipulate, store and transmit large quantities of information at a very low cost (Sheehan, 2000). Because of its low cost, information flows across the Internet and, consequently, the application of knowledge to all aspects of the economy are greatly facilitated.

Several studies have attempted to identify the contributing factors for developing knowledge based economy as well as figure out those issues which are preventing other countries from becoming a Knowledge Based Economy (KBE). Some of those studies are as follows,

(Lorena et al., 2007)predicts that Europe would becomethe most competitive and dynamic knowledge-based economy in the world, capable of sustained economic growth with more and better jobs and greater social cohesion by ensuring efficiency in transforming its innovation inputs into innovation outputs.

Laura James et al., (2011) study revealed that the development of knowledge based economy requires individuals to acquire measurable knowledge or skills in the form of qualifications through formal education and training, which will allegedly improve national economic competitiveness and productivity.

Nyende et al., (2008) indicated that in spite of its major development challenges, Africa is showing signs of a reversed trend: economies had been growing for the sixth consecutive year, conflicts were declining and many countries were now managing democratic political transitions.

Krmpotić, (2011) Study result revealed that that there are a number of significant factors and variables of knowledge economy that have an impact on the achieved development of the three income groups.

Đonlagić, (2012) revealed in his study that higher education is of great importance for the knowledge economy in Bosnia and Herzegovina.

Junoh, (2004) Study revealed that, the neural network technique has an increased potential to predict GDP growth based on knowledge based economy indicators compared to the traditional econometric approach.

\section{ObJectives Of the Study}

The broad objective of the study is to identify essential factors for developing knowledge based economy of Bangladesh.

The specific objectives of the study are:

- To identify variables which contribute significantly to the development of knowledge based economy

- To assess current status of knowledge based economy
- To compare performance with other countries for identifying challenges and opportunities for development of knowledge based economy(KBE)

\section{Driver of KNOWLEDGE based ECONOMY}

Development of a knowledge economy involves changes across many aspects of the economy. There are numerous knowledge economy frameworks which provide a basis for knowledge economy development. But, not all of these frameworks are suitable for each country and its specifics. Based on experiences of many countries The World Bank Institute (WBI) introduced indicators that provide guidance in measuring knowledge economy development. The purpose of knowledge economy measurement is to describe the progress of a country in development of a knowledge economy. Based on empirical studies by the OECD and WBI a framework has been introduced to assist policymakers in knowledge economy development.

The conceptual framework designed and applied by WBI indicates that developing a knowledge economy requires the following key pillars: (1) effective government institutions and economic incentives, (2) education and training, (3) ICT and infrastructure and (4) developed system of research and development.

Effective government institutions and economic incentives The influence of effective government on economic performance is evident in developed countries. Experiences in developing countries show a strong correlation between good governance and per capita income. Economic incentives in the form of good tax laws, financial initiatives and flexible intellectual property regulation create a more competitive business environment. This is important for the creation and accumulation of new knowledge. Generally speaking, in a country with poor competition and with the lack of pressure to create new products and services the level of creation of new knowledge is very low and therefore the level of economic growth as well.

\section{Education and training}

The second pillar of knowledge economy is an effective and productive educational system which can fulfill the needs of the economy. The importance of human capital is a result of the need for better skills (e.g. Team work or cognitive skills) and lifelong learning in order to be able to cope with business changes and challenges. The effect of knowledge and knowledge accumulation on the level of productivity indicates that an adequate education system is necessary to ensure knowledge transfer in the society. The educational system is a key factor in thecreation of innovative culture which is necessary for successful development of a modern economy. The educational system should ensure knowledge flow between individuals, companies and institutions through cooperation between educational institutions and 
companies which lowers the research and development costs in companies.

Information-communication technologies and infrastructure

Literature on the knowledge economy emphasizes the importance of ICT on the knowledge economy and the country's economic development. But the full potential of ICT and ICT infrastructure cannot be utilized with uneducated workforce, traditional management practices and an inadequate legal framework. ICT does not generate knowledge, but they allow individuals, companies and other organisations to access, use and transfer knowledge in a fast and cost efficient manner. Development of ICT and their applicationshave contributed to a significant increase of demand for educated workers. For transition countries development of ICT can be an especially significant factor for achieving economic development and growth.

\section{Research and development $(R \mathcal{E} D)$ and innovation}

Developed innovation culture depends on the government of a country which should create an environment which enables innovation in the private sector but also in the public sector. R\&D activities require significant long term investments.

This study is a step towards identifying factors necessary for developing knowledge based economy as well as figuring out areas where significant efforts need to be initiated in order to accelerate the development process towards KBE of Bangladesh.

\section{METHODOLOGY OF THE STUDY}

Different frameworks have been developed by international organizations, including the World Bank (WB), Organization for Economic Co-operation and Development (OECD), and Asia Pacific Economic Cooperation (APEC). This section reviews the frameworks or methodologies asserted by different international economic organizations of assessing knowledge based economy performance.

\section{OECD framework}

OECD started to conduct research on the KBE and attempted to compile statistical indicators on the $\mathrm{KBE}$ as early as in 1996, evident in their work on developing and publishing science and technology (S\&T) indicators (OECD, 1996). In general, it was suggested by OECD that improved indicators for the $\mathrm{KBE}$ are needed for the following tasks:

1. Measuring knowledge inputs;

2. Measuring knowledge stocks and flows;

3. Measuring knowledge outputs;

4. Measuring knowledge networks; and

5. Measuring knowledge and learning

The principal knowledge input indicators are expenditure on research and development (R\&D); employment of engineers and technical personnel; patents; and international balance of payments. Measuring the stock of physical capital available would seem almost impossible. As such, only a few proxy indicators have been suggested by OECD. This also applies to the flow of knowledge. As regards knowledge outputs, only rough indicators have been developed, including the delineation of a list of high technology industries.

\section{APEC framework}

APEC approached the KBE from a perspective similar to that of the OECD Growth Project. In 2000, the APEC Economic Committee, in partnership with organizations in member economies, analyzed the underpinnings of the KBE by examining the empirical evidence from the individual economies concerned. The work concluded that four dimensions characterize KBEs and are largely responsible for the strong economic performance of some economies over the last few decades (APEC, 2000). The four dimensions so deduced are:

(i) Innovation and technological change are pervasive and supported by an effective national innovation system;

(ii) Human resources development is pervasive;

(iii) An efficient infrastructure operates, particularly in ICT; and

(iv) The business environment is supportive of enterprise and innovation.

\section{World Bank Framework}

In 1999, the World Bank Institute launched a project entitled "Knowledge for Development" (K4D). Its aims were to raise awareness among national policymakers about the powerful growth effects of knowledge and to encourage economists to combine global and local knowledge in order to accentuate comparative advantages (World Bank, 2002)

The World Bank has set these elements as the four pillars of the knowledge economy within the Knowledge Economy Framework. These pillars are (World Bank, 2012):

1. An economic incentive and institutional regime that provides good economic policies and institutions that permit efficient mobilization and allocation of resources and stimulate creativity and incentives for the efficient creation, dissemination and use of existing knowledge;

2. Educated and skilled workers who can continuously upgrade and adapt their skills to efficiently create and use knowledge;

3. A modern and adequate information infrastructure that can facilitate the effective communication, dissemination and processing of information and knowledge.

4. An effective innovation system of firms, research centers, universities, consultants and other organizations that can keep up with the knowledge revolution, tap into the growing stock of global knowledge and assimilate and adapt it to local needs; 


\begin{tabular}{|c|c|c|c|}
\hline \multicolumn{4}{|c|}{ Figure-1 The four pillars of the knowledge economy } \\
\hline $\begin{array}{l}\text { Pillar 1 } \\
\text { Economic and } \\
\text { institutional regime }\end{array}$ & $\begin{array}{l}\text { Pillar } 2 \\
\text { Education and skills }\end{array}$ & $\begin{array}{l}\text { Pillar } 3 \\
\text { Information and } \\
\text { communication } \\
\text { infrastructure }\end{array}$ & $\begin{array}{l}\text { Pillar } 4 \\
\text { Innovation system }\end{array}$ \\
\hline $\begin{array}{l}\text { The country's economic and } \\
\text { institutional regime must provide } \\
\text { incentives for the efficient use of } \\
\text { existing and new knowledge and } \\
\text { the flourishing of } \\
\text { entrepreneurship }\end{array}$ & $\begin{array}{l}\text { The country's people } \\
\text { need education and } \\
\text { skills that enable them } \\
\text { to create and share, } \\
\text { and to use it well. }\end{array}$ & $\begin{array}{l}\text { A dynamic information } \\
\text { infrastructure is needed to } \\
\text { facilitate the effective } \\
\text { communication, and } \\
\text { dissemination, and and } \\
\text { processing of information }\end{array}$ & $\begin{array}{l}\text { The country's innovation system-firms, } \\
\text { research centers, universities, think tanks, } \\
\text { consultants, and other organizations-must be } \\
\text { capable of tapping the growing stock of global } \\
\text { knowledge, assimilating and adapting it to local } \\
\text { needs, and creating new technology. }\end{array}$ \\
\hline
\end{tabular}

The Knowledge Economy Framework postulates that the amount of knowledge and how it is used are key determinants of total factor productivity (TFP). Strengthening the four pillars of the knowledge economy will lead to an increase in the quantity and quality of the pool of knowledge available for economic production in any country. This in turn will increase productivity and, thus, economic growth (Dahlman, 2003).

\section{Knowledge Indexes}

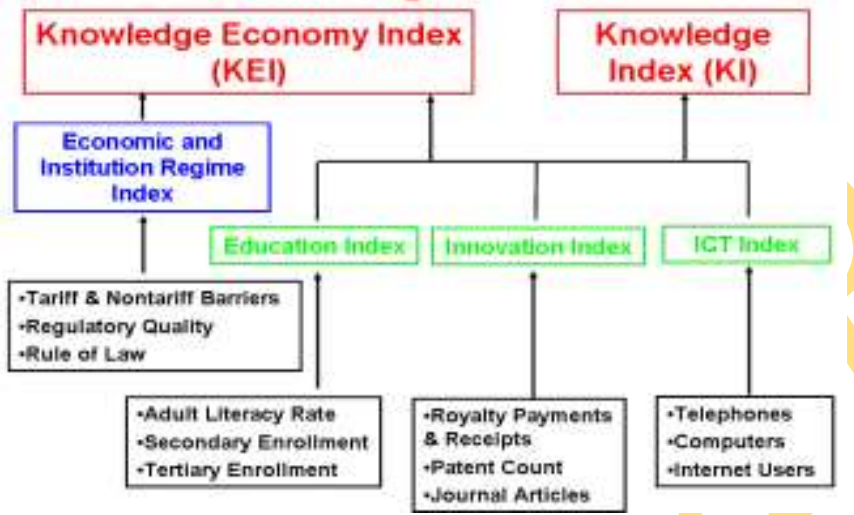

Calculation of the KEI is based on the average of the normalized performance scores of a country or region on all four pillars of the knowledge economy -economic incentive and institutional regime, education and human resources, the innovation system and ICT (Dahlman, 2003).

Figure 02: The 04 indicators of knowledge economy pillars
Figure-1 shows the four pillars of the knowledge economy with three key variables, representing each pillar. In calculating the KEI and KI indices, as well as the indices of the four pillars of the knowledge economy, the World Bank ranks countries, according to a single model of building a knowledge based economy which it applies to all countries.

\section{MeAsuring the KNOWLEDGE ECONOMY IN BANGLADESH}

To assess the readiness of a country for the knowledge economy through use of indicators a country can be benchmarked. For this purpose WBI developed a methodology and a database covering data for countries computing them into indexes that reflect a country's performance regarding the knowledge economy pillars. The selection of 4 (four) indicators gives an overall view of Bangladesh's knowledge economy readiness in comparison with Developing countries.

A country is able to use this methodology in order to identify problems and opportunities; however it does not reveal the solution to how to use this opportunity. Identification of strengths and weaknesses is possible by comparison to countries in the region since it is important for these countries to coordinate their economic policies. Measurement of the level of readiness for knowledge economy development in Bangladesh is the first step in understanding the possibilities of this country.

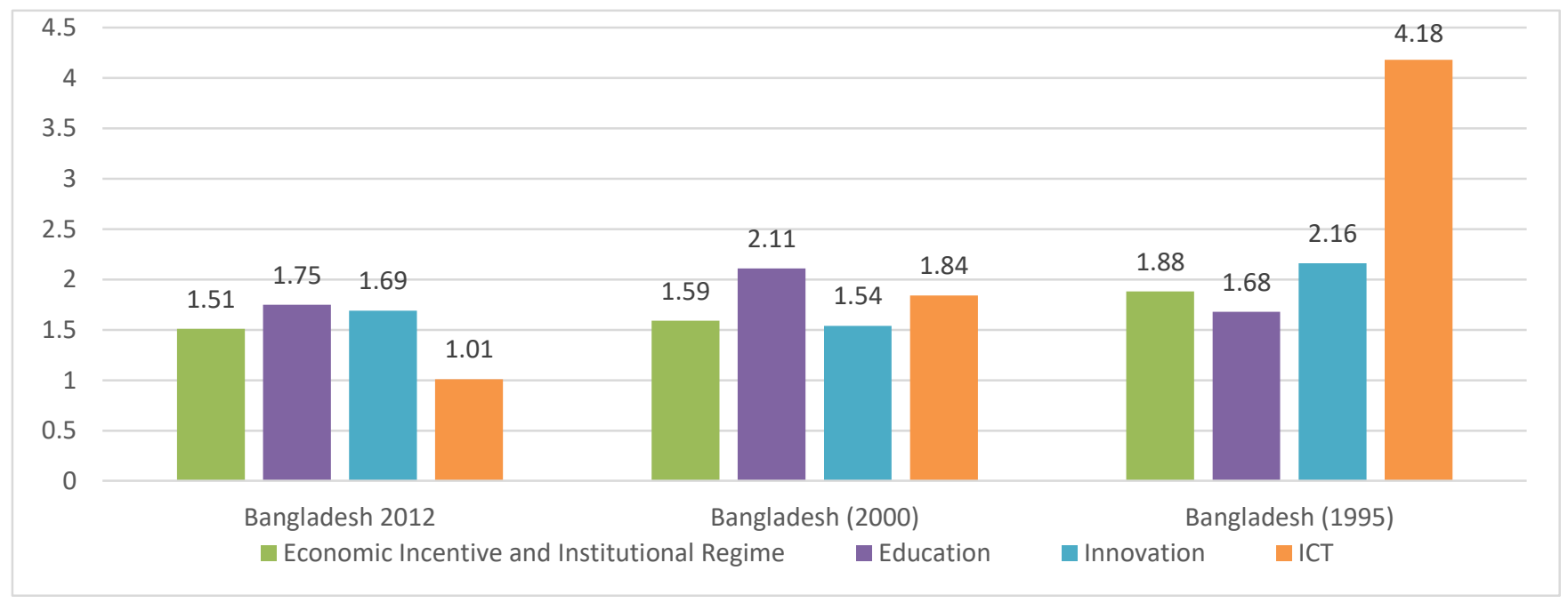

Source: World Bank database: (2012) 
The values of the selected 04 (four) indicators for knowledge economy pillars are presented inFigure-2.It is obvious that the levels of success of the pillars vary. Examination of indicators reveals varying degrees of achievement. The best normalized values Bangladesh has achieved among all indicators are ICT (4.18) in 1995, education (2.11) and (1.75) in 2000 and 2012 respectively. In 1995, Bangladesh has shown impressive development in ICT having normalized value 4.18 followed by innovation
(2.16). In year 2000, knowledge economy indicators show downturn, all aspect by showing dismal performance in developing knowledge based economy indicating values range from 2.11 to 1.54 and such trend continue in 2012 by showing least possible development indicator values range from 1.75 to 1.01 . The overwhelming fact is significant a change was noticed in regards to the development of ICT, one of the key indicators of knowledge based economy development.

Figure-3 Knowledge Economy Index (KEI): South Asia

\section{Knowledge Economy Index (KEI): Southasia}

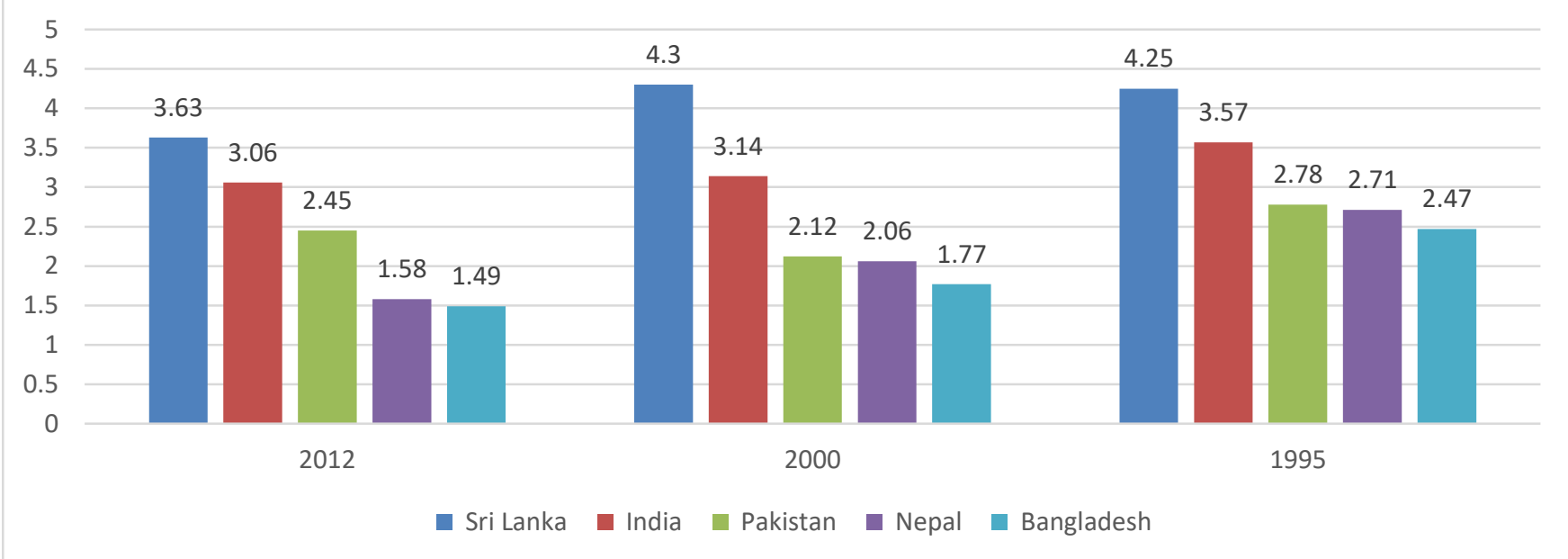

Source: World Bank database: 2012

From Figure-3 it is obvious that among South Asian countries, Sri Lanka is the most successful (the index values are 4.25, 4.3 and 3.63) in regards to developing knowledge based economy, followed by India $(3.57,3.14$ and 3.06), Pakistan (2.78, 2.12 and 2.45), Nepal (2.71, 2.06 and 1.58). Bangladesh shows least successful among all South Asian countries.

\section{MAJor Challenges for the KnOWLedge BASEd ECONOMY IN BANGLADESH}

Bangladesh's efforts towards a knowledge-based economy would pose some challenges and the road ahead would not be rosy. First, the major challenge for Bangladesh is to be able to convince the different sectors in the country about the importance of moving towards such a new economy. There is also the need to be able to change the mindset of the people from thinking about the production for the old economy to that of producing for the new. This would require an innovative and creative way of thinking. This kind of thinking would lead to the production of innovative products for the global marketplace in the knowledge-based economy.

Second, a lot of people are still in the dark about what the knowledge-based economy is all about. The government would have to educate these masses as to what it entails and its importance to the growth and development efforts of
Bangladesh. To develop a competitive edge in a knowledgebased economy, Bangladesh would need a highly skilled manpower. Another important challenge is building an innovative capacity in the country to be able to develop goods and services for the knowledge-based economy. Such would not happen without a firm commitment on the part of the government. A commitment of incentives and recognition are a good place to start. It would also require a proactive approach where the requisite resources should be provided for research to develop products and processes to help the country to compete in the knowledge-based economy. To bring about innovation, the government must foster an environment where creative and innovative thinking is rewarded. Furthermore, the challenge of the government should be in the direction of its energies to garner funds and make such funds available to local entrepreneurs to enable them to produce competitive goods and services for the knowledge-based economy.

\section{Key Areas for Developing Knowledge based ECONOMY OF BANGLADESH}

Development of knowledge based economy requires sustainable development in every aspects which have significant contribution in this process. For building a knowledge based economy of Bangladesh, it is imperative to focus on the following issues very meticulously 


\section{Building the Knowledge Manpower}

Human capital will be the key driver for growth in the knowledge-based economy and will determine the competitive position of the nation. The successful development of the knowledge-based economy will, therefore, largely depend on the quality of the education and training system. The institutional framework to ensure an adequate supply of appropriately qualified and skilled manpower and to continually retrain them will be put in place.

The education system from pre-school level will be reviewed to enable it to meet the manpower requirements of the knowledge-based economy. The key areas that will be reviewed include the curriculum, teaching methods, enrollment at the tertiary level and the quality of the teaching profession. The curriculum will emphasize the teaching of core competencies and will be in line with changing manpower requirements. Vocational and technical education and training will be given greater prominence and will be refocused to produce the skills required by the knowledge-based economy. In addition, teaching methods will be transformed to promote creativity, originality, innovation as well as thinking and analytical skills. The use of IT as a tool for teaching and learning will be made more pervasive. Public and private tertiary institutions will need to become more marketdriven and proactive by moving beyond traditional areas to new fields of education required by a maturing knowledge-based economy.

\section{Intensifying Research and Development}

Bangladesh needs to harness its potential to drive the key sectors in R\&D and become a competitive knowledgebased economy. In this context, during the development period, priority will be accorded to increasing R\&D manpower, improving related infrastructure, strengthening existing mechanisms for supporting R\&D and technology development and diffusion. These will provide the basis for a well-functioning national innovation system.

To provide an impetus for R\&D initiatives, the public sector will increase the proportion of the budget allocated for this purpose. The funding mechanism for $R \& D$ activities will be streamlined to ensure optimum utilization of funds. Proposals for research will be evaluated by a panel of experts, including foreigners, in the proposed area of research. The corporate sector, including the small- and medium-scale enterprises (SMEs), will be provided significant incentives to allocate a greater proportion of their revenue for $R \& D$.

\section{Accelerating the Development of Info-structure}

Concerted efforts will have to be initiated in order to ensure equitable distribution and provision of telecommunications infrastructure and services to underserved areas and groups to bring them into the mainstream of the knowledge-based economy so that it can support the rapid flow and accessibility of information within the country and across countries at competitive prices.

A more integrated and comprehensive approach will be taken in developing the regulatory environment and institutional framework to create a conducive environment for the development of the knowledge-based economy and proliferation of knowledge activities. The legal framework will be fine-tuned to support the orderly operation of electronic activities such as e-commerce, e-government, efinancing and e-education as well as to support a flexiworking system. Legislation relating to intellectual property rights and protection of privacy and security will be reviewed to improve the flow of information and knowledge.

\section{Restructuring the Financial System}

The financial system, including sources of financing, rules and regulations as well as institutions, will be realigned to support the growth of knowledge-based economy activities and industries. The banking system, which currently serves as the main source for corporate financing will introduce innovative lending instruments and develop capability to assess future cash flow potential of knowledge-based projects.

In addition, the government will also encourage the inflow of foreign venture capital funds as well as increasing foreign equity ownership in order to tap foreign expertise and experience in this area.

Furthermore, capital market will become an increasingly important source for raising funds for new and expanding companies engaged in knowledge-based activities. Initiatives to develop the capital market will be accelerated with the introduction of innovative funding instruments and the development of alternative capital raising avenues to finance high-technology companies.

\section{Raising the Knowledge-content in Agriculture, Manufacturing and Services Sectors}

While all sectors of the economy are expected to become more knowledge intensive, efforts will be intensified to increase the knowledge-content in all sectors, especially agriculture, Manufacturing and service sector. The greater application of knowledge will strengthen as well as increase the dynamism and competitiveness of these sectors and contribute to sustained rapid economic growth. In addition, the rapid advancements in ICT, which will underpin the growth of the knowledge-based economy, will itself spawn new activities and areas of investment in these sectors.

To remain competitive and maintain its position as an important contributor to economic growth, the manufacturing sector will have to undertake rapid structural change. Firms must aspire to move up the technology ladder to produce high-end products that generate greater value added. Firms will also be encouraged to move along the value chain into knowledgeintensive activities. 
In the services sector, efforts will be taken to modernize and enhance its efficiency so that it becomes more competitive as well as supports an advanced industrial sector. While developing the traditional sectors, there is the need to identify and develop new service products that will be generated by the knowledge based economy.

In order to ensure that SMEs are brought into the mainstream of the knowledge-based economy, the Government will formulate programs to accelerate the creation of a critical mass of capable, progressive and efficient SMEs. To facilitate the participation of SMEs in knowledge-intensive activities, particularly in the manufacturing and services sectors, they will be encouraged to establish supply linkages with large hightechnology companies as well as form smart partnerships and strategic alliances with foreign high-technology SMEs. The Government will facilitate the access of SMEs to venture capital funding as well as funds to carry out R\&D so that they can design, innovate and produce components and products and thereby effectively participate in the new industries emerging in the knowledge based economy. Industry associations will also need to be more active and committed in assisting the development of SMEs so that they will be able to partake in the opportunities that will be generated in the knowledge-based economy.

\section{Preparing the Private Sector for the Change}

The private sector will continue to be the engine of growth in the knowledge based economy. The private sector, including the SMEs, will have to swiftly redefine their production processes by applying appropriate and costefficient technology. They must also take a global view as markets will become virtual and borderless. Traditional modes of sourcing inputs and marketing products will have to be complemented by the greater use of e-trading and e-business tools. In addition, the private sector will need to create new value by developing capacity to undertake R\&D, product development and innovation, as well as package, market and distribute their products efficiently and speedily.

\section{Conclusion}

As it is evident from this analysis that the knowledgebased economy presents the way forward to achieve sustainable rapid growth and remain globally competitive in the medium and long term. In order to develop a knowledge-based economy, it is imperative to address the issues and resolve them swiftly. While Bangladesh has already set some of the basic foundations of a knowledgebased economy, efforts must be accelerated in the key areas of HRD, S\&T and R\&D, info-structure, financing and equity, which are fundamental to building knowledgebased economy of Bangladesh.

Building a knowledge-based economy is a long process involving radical and far reaching changes. The transformations that a particular country should make depend primarily on its achieved level of economic development. Scenarios for building a knowledge-based economy cannot be common to all countries. The priority will be given:

- Improvement of the quality of the labor force, especially through better management education and by controlling and reducing the brain drain.

- Intensive application of ICT, especially through increasing the number of computers in the population and providing greater availability of e-government and other e-services.

- Improvement of Law and Institutions, in particular by exerting greater control, combating corruption and strengthening political stability.

- Becoming successful in the knowledge based economy should ensure Strong economic fundamentals.

\section{SCOPE FOR FURTHER RESEARCH}

The study focused on identifying the factors be considered while developing knowledge based economy in a broader sense. This study does not look into the effect of knowledge based economy on overall economic development. Thus, the study paves the avenue for following further research agenda:

- An assessment can be done in regards to identifying prioritize sector for ensuring development of knowledge base economy.

\section{REFERENCE}

Bank, (2002). 'Knowledge Assessment Scorecard'. 2002: World Bank Institute.

Brinkley, I. (2006). 'Defining the knowledge economy'. The Work Foundation, London:

Bucharest, R (2007). 'Indicators for Knowledge Economy'. Informatica Economicăpp.: 60-63.

Chen, DD (2005), 'The Knowledge Economy, the KAM Methodology and World Bank Operations'. World Bank. Retrieved from http:/ / papers.ssrn.com/sol3/papers.cfm?abstract_id=841625

Dahlman, CJ (2003),'using knowledge for development: a general framework $\mathcal{E}$ preliminary assessment of China'. Retrieved from www.developmentgateway.org/node/130667/sdm/docvie $\mathrm{w}$ ?docid $=42$

Đonlagić, AK (2012), 'Determining Key Factors For Knowledge Economy Development in Bosnia and Hercegovina'. Management Knowledge and Learning International Conference, Pp. 413-421.

GeneBellinger, DC (2004), 'Data, Information, Knowledge, and Wisdom - Systems Thinking'.

Jones, AB (1999),'Knowledge Capitalism-Business', Work and Learning in the New Economy. University Press.

Junoh, MZ (2004),'Predicting GDP Growth in Malaysia using knowledge based economy indicator. A comparison between natural network and economic approach'. Sunway College Journal, pp.39-50.

Krmpotić, DS (2011), 'Knowledge Economy Factors and the Development of Knowledge-based Economy'. Croatian Economic Survey, PP.105-141.

Laura, DG (2011), 'from learning for the knowledge-based economy to learning for growth: re-examining clusters, innovation and qualifications'. Centre for Learning and Life Chances in 
Knowledge Economies and Societies, Retrieved from http:/ / www.llakes.org

Leadbeater, C (1999), 'New measures for the New Economy'.

Lorena, BR (2007), 'Indicators for Knowledge Economy'. Revista Informatica Economică, pp.60-63.

Lundwall, FD (1996), Knowledge-based Economy: From the Economics of Knowledge to the Learning Economy in Employment and Growth in the Knowledge-based Economy', Paris.

M.Daley, W (2000), Digital economy 2000', Retrieved from http://www.esa.doc.gov/de2k.htm.

Mohaimen MA. 2013. Talent Management: Three new Perceptions intended for managing and retaining Talent in Bangladesh Asian Business Review, 3, 7-15.

Nyende, AB (2008),'Growing a Knowledge-Based Economy: Evidence from Public Expenditure on Education in Africa'. African Development Bank.

OCDE. (1996). 'The Knowledge-Based Economy'. Paris, Organization for Economic Co-Operation and Development.
OECD (1996), 'The Knowledge-based Economy'. Paris, OECD / STI Outlook.

Rahman AF and Khan AR. 2012. Measuring Underground Economy of Bangladesh: Transaction Approach Global Disclosure of Economics and Business, 1, 9-17.

Sheehan, H (2000), 'A primer on the knowledge economy'. Retrieved from http://www.cfses.com/primer.htm.

Tinne WS. 2013. Nation Branding: Beautiful Bangladesh Asian Business Review, 2, 31-36.

Tocan, MC (2012), 'Knowledge Based Economy Assessment'. Journal of Knowledge Management, Economics and Information Technology.

World Bank (2012), 'Measuring Knowledge in the World's Economies'. World Bank Institute. Retrieved from http:/ / siteresources.worldbank.org/INTUNIKAM/Resour ces/KAMbooklet.pdf 


\section{How to Cite}

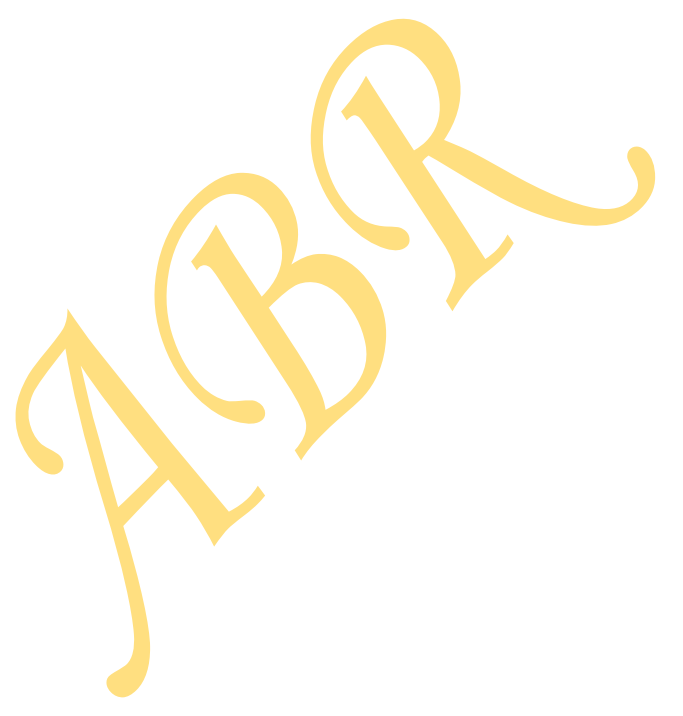

Qamruzzaman M and Ferdaous J. 2014. Building a Knowledge-Based Economy in Bangladesh Asian Business Review, 4, 119-128. 